\title{
Land use change analysis in the Zhujiang Delta of China using satellite remote sensing, GIS and stochastic modelling
}

\section{Qihao Weng}

\author{
Department of Geography, Geology, and Anthropology, Indiana State University, Terre Haute, \\ IN 47809, USA
}

Received 27 April 2000; accepted 31 August 2001

\begin{abstract}
Rapid land use change has taken place in many coastal regions of China such as the Zhujiang Delta over the past two decades due to accelerated industrialization and urbanization. In this paper, land use change dynamics were investigated by the combined use of satellite remote sensing, geographic information systems (GIS), and stochastic modelling technologies. The results indicated that there has been a notable and uneven urban growth and a tremendous loss in cropland between 1989 and 1997. The land use change process has shown no sign of becoming stable. The study demonstrates that the integration of satellite remote sensing and GIS was an effective approach for analyzing the direction, rate, and spatial pattern of land use change. The further integration of these two technologies with Markov modelling was found to be beneficial in describing and analyzing land use change process.
\end{abstract}

(C) 2002 Elsevier Science Ltd.

Keywords: Land use management, satellite remote sensing, GIS, Markov modelling, South China.

\section{Introduction}

Since 1978, when China initiated economic reform and an open-door policy, rapid land use and land cover change has taken place in most of its territory. Rapid industrialization and urbanization has resulted in the loss of a significant amount of agricultural land. This is especially true in many coastal regions and cities, such as the Zhujiang Delta, where maximizing economic efficiency is the top priority of development. Because of the lack of appropriate land use planning and the measures for sustainable development, rampant urban growth and massive disappearance of agricultural land have had severe environmental consequences. Moreover, the dike-pond system, an environmentally conserving agriculture-aquaculture technology, specially developed for utilizing the lowlying flood-prone environment in the delta, has also undergone changes. All these changes have

Email: geweng@scifac.indstate.edu the potential to undermine the long-term harmonious people-environment relationship. There is an urgent need for evaluating the magnitude, pattern, and type of land use and land cover changes and for projecting future land development.

Satellite remote sensing, in conjunction with geographic information systems (GIS), has been widely applied and been recognized as a powerful and effective tool in detecting land use and land cover change (Ehlers et al., 1990; Meaille and Wald, 1990; Treitz et al., 1992; Westmoreland and Stow, 1992; Harris and Ventura, 1995; Yeh and Li, 1996, 1997, 1999; Weng, 2001). Satellite remote sensing provides cost-effective multi-spectral and multitemporal data, and turns them into information valuable for understanding and monitoring land development patterns and processes and for building land use and land cover data sets. GIS technology provides a flexible environment for storing, analyzing, and displaying digital data necessary for change detection and database development. Satellite imagery has been used to monitor discrete land cover types by spectral classification or to estimate 
biophysical characteristics of land surfaces via linear relationships with spectral reflectances or indices (Steininger, 1996). Post-classification comparison and multi-date composite image change detection are the two most commonly used methods in the change detection (Jensen, 1996). In recent years, the techniques of satellite remote sensing and GIS have been increasingly used to examine the spatial and temporal patterns of land use and land cover change in China, especially related to urban growth (Dai et al., 1996; Yeh and Li, 1996, 1997, 1999; Chen et al., 2000). Scale-dependent relationships between Chinese land uses and driving forces have also been examined using correlation and regression analyses (Verburg and Chen, 2000).

Remote sensing and GIS based change detection studies have predominantly focused on providing the knowledge of how much, where, what type of land use and land cover change has occurred. Only a few models have been developed to address how and why the changes occurred. The models of land use and land cover change process fall into two groups: regression-based and spatial transition-based models (For good summaries of these models, please refer to review articles by Baker (1989), Lambin (1997), and Theobald and Hobbs (1998)). The majority of research utilizes regression-based approach, which relates the locations of land use and land cover change to a set of spatially explicit variables, and uses models such as logistic (Landis, 1994; Turner et al., 1996; Wear et al., 1998), and hedonic price models (Geohegan et al., 1997). Spatial transition-based models often refer to cellular automaton simulation models, which allow for predicting future land development based on probabilistic estimates with Monte Carlo or other methods (Clarke et al., 1997; Clarke and Gaydos, 1998). One crucial limit to the development of the process models is, however, the deficiency of explicit modelling tools for change processes in the current generation of remote sensing and GIS systems. Equally important is the issue of data availability (Baker, 1989). Moreover, few studies have attempted to link satellite remote sensing and GIS to stochastic modelling methods in land use and land cover change studies, in spite of the fact that the techniques for such linkages have become mature in recent years due to advances in the technology of GIS and its integration with remote sensing. This missing linkage has hindered modelling and assessing the dynamics of land use and land cover change, and significantly impeded progress towards understanding of earth-atmosphere interactions, biodiversity loss, and global environmental change.

This paper presents a method that combines satellite remote sensing, GIS, and Markov modelling to analyze and predict land use and land cover changes in the Zhujiang Delta of southern China between 1989 and 1997. The techniques of satellite remote sensing and GIS are integrated to quantify and analyze land use and land cover changes using Landsat TM data and field surveyed in situ data. Markovian modelling is then used to examine the stochastic nature of the land use and land cover change data and to project the stability of future land development in the region.

\section{Markov modelling of land use and land cover changes}

Markov chains have been used to model changes in land use and land cover at a variety of spatial scales. Changes in land use were often separated from changes in land cover/vegetation type, in spite of similarities in method and approach. Markov analysis of vegetation types tends to focus on a small area of less than a few hectares or on a single small plot. When a few hundred hectares of land are involved, data sampling is usually applied to limit the workload to scattered plots or transects (Baker, 1989). On the other hand, land use studies using Markov chain models tend to focus on a much larger spatial scale, and involve both urban and non-urban covers (Drewett, 1969; Bourne, 1971; Bell, 1974; Bell and Hinojosa, 1977; Robinson, 1978; Jahan, 1986; Muller and Middleton, 1994). All of these studies use the first-order Markov chain models. The order of the Markov chains has only been formally tested in a few studies (Bell, 1974; Robinson, 1978). Stationarity has usually been assumed, except in a few instances where it has been tested (Bourne, 1971; Bell, 1974; Bell and Hinojosa, 1977). Brown et al. (2000) recently presented an approach to estimating transition probabilities between two binary images in a study of land use and land cover relationship in the Upper Midwest, USA. This approach, according to Huber (2001), needs to be improved and generalized in order to estimate properly Markov transitions from a pair of images.

Markov chain models have several assumptions (Parzen, 1962; Haan, 1977; Wang, 1986; Stewart, 1994). One basic assumption is to regard land use and land cover change as a stochastic process, and different categories are the states of a chain. A 
chain is defined as a stochastic process having the property that the value of the process at time $t, X_{\mathrm{t}}$, depends only on its value at time $t-1, X_{\mathrm{t}-1}$, and not on the sequence of values $X_{\mathrm{t}-2}, X_{\mathrm{t}-3}, \ldots, X_{0}$ that the process passed through in arriving at $X_{\mathrm{t}-1}$. It can be expressed as:

$$
\begin{aligned}
P\left\{X_{\mathrm{t}}\right. & \left.=a_{\mathrm{j}} \mid X_{0}=a_{0}, X_{1}=a_{1}, \ldots, X_{\mathrm{t}-1}=a_{\mathrm{i}}\right\} \\
& =P\left\{X_{\mathrm{t}}=a_{\mathrm{j}} \mid X_{\mathrm{t}-1}=a_{\mathrm{i}}\right\}
\end{aligned}
$$

Moreover, it is convenient to regard the change process as one which is discrete in time $(t=$ $0,1,2, \ldots)$.

The $\mathrm{P}\left\{X_{\mathrm{t}}=a_{\mathrm{j}} \mid X_{\mathrm{t}-1}=a_{\mathrm{i}}\right\}$, known as the one-step transitional probability, gives the probability that the process makes the transition from state $a_{i}$ to state $a_{j}$ in one time period. When $\ell$ steps are needed to implement this transition, the $\mathrm{P}\left\{X_{\mathrm{t}}=a_{\mathrm{j}} \mid X_{\mathrm{t}-1}=a_{\mathrm{i}}\right\}$ is then called the $\ell$-step transition probability, $P_{\mathrm{ij}}^{(\ell)}$. If the $P_{\mathrm{ij}}^{(\ell)}$ is independent of times and dependent only upon states $a_{\mathrm{i}}, a_{\mathrm{j}}$, and $\ell$, then the Markov chain is said to be homogeneous. The treatment of Markov chains in this study will be limited to first order homogeneous Markov chains. In this event:

$$
P\left\{X_{\mathrm{t}}=a_{\mathrm{j}} \mid X_{\mathrm{t}-1}=a_{\mathrm{i}}\right\}=P_{\mathrm{ij}}
$$

where $P_{\mathrm{ij}}$ can be estimated from observed data by tabulating the number of times the observed data went from state $i$ to $j, n_{\mathrm{ij}}$, and by summing the number of times that state $a_{\mathrm{i}}$ occurred, $n_{\mathrm{i}}$. Then

$$
P_{\mathrm{ij}}=n_{\mathrm{ij}} / n_{\mathrm{i}}
$$

As the Markov chain advances in time, the probability of being in state $\mathrm{j}$ after a sufficiently large number of steps becomes independent of the initial state of the chain. When this situation occurs, the chain is said to have reached a steady state. Then the limit probability, $P_{\mathrm{j}}$, is used to determine the value of $P_{\mathrm{ij}}^{(\ell)}$ :

$$
\lim _{\mathrm{n}} P_{\mathrm{ij}}^{(\mathrm{n})}=P_{\mathrm{j}}
$$

where:

$$
\begin{aligned}
& P_{\mathrm{j}}=P_{\mathrm{i}} P_{\mathrm{ij}}^{(\mathrm{n})} \quad j=1,2, \ldots, m(\text { state }) \\
& P_{\mathrm{i}}=1 \quad P_{\mathrm{j}}>0
\end{aligned}
$$

As land use and cover change reflects the dynamics and interplay of economic, social, and biophysical factors over time, it would be implausible to expect stationarity in land use/cover data. However, it might be practical to regard land use/cover change to be reasonably stationary if the time span is not too great.

Markov modelling of land use and land cover changes have not been substantial by the use of satellite imagery and digital image processing technique. Previous studies mostly utilize data sampled from field surveys, existing maps, or aerial photography (Drewett, 1969; Bourne, 1971; Bell, 1974; Bell and Hinojosa, 1977; Robinson, 1978; Jahan, 1986; Muller and Middleton, 1994). Data uncertainty in these studies remains relatively high, because only a certain amount of sites was sampled. The use of satellite imagery would create an opportunity for improved analysis. Moreover, the Markov models have been mostly employed for studies around a city or a slightly larger area, with a regional concentration in North America. The application of stochastic models to simulate dynamic systems such as land use and land cover changes in a developing nation is rare. Clearly, much work needs to be done in order to develop an operational procedure that integrates the techniques of satellite remote sensing, GIS, and Markov modelling for monitoring and modelling land use and land cover changes.

\section{Study area}

The Zhujiang (literally 'the Pearl River') Delta, located between latitudes $21^{\circ} 40^{\prime} \mathrm{N}$ and $23^{\circ} 00^{\prime} \mathrm{N}$, and longitudes $112^{\circ} 00^{\prime} \mathrm{E}$ and $113^{\circ} 20^{\prime} \mathrm{E}$, is the third biggest river delta in China. This study focuses on the core area of the delta, which has an area of 15112 sq. km (Figure 1). Geomorphologically, the delta consists of three sub-deltas formed by sediments, namely, the Xijiang, Beijiang, and Dongjiang Deltas. The process of sedimentation still continues today, and the delta is extending seaward at a rate of $40 \mathrm{~m}$ per year (Gong and Chen, 1964). The climate of the delta is basically tropical with an average annual temperature between $21^{\circ} \mathrm{C}$ and $23^{\circ} \mathrm{C}$, and an average precipitation from 1600 to $2600 \mathrm{~mm}$. Natural vegetation is predominantly evergreen.

Economically, the Zhujiang Delta is the largest area of economic concentration in South China. Since 1978, it has had a dramatic economic expansion under China's economic reform policies, and therefore has been regarded as a model for Chinese regional development. The establishment of Special Economic Zones and the Economic Open Zone has encouraged foreign firms to locate their factories there as village-township enterprises. 


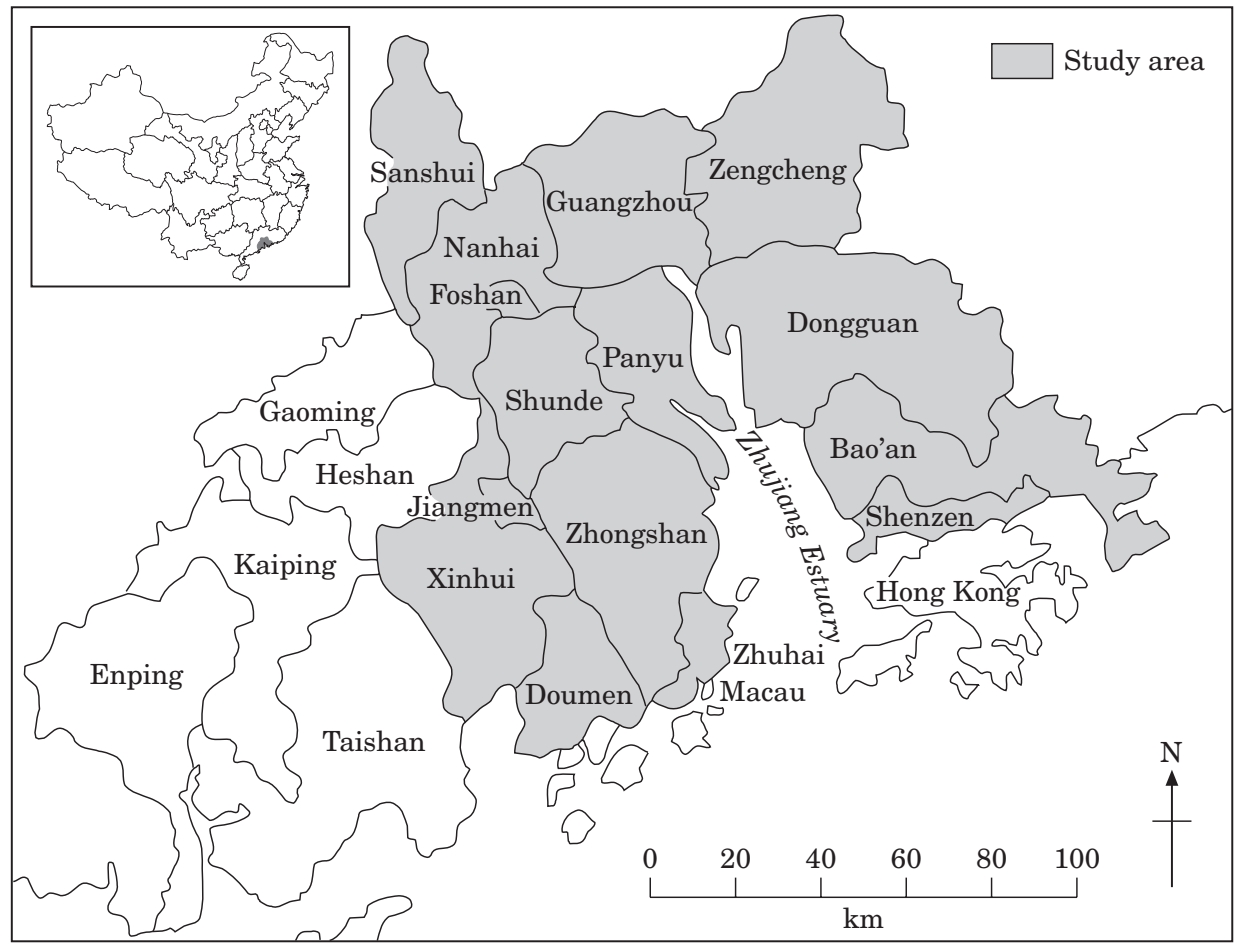

Figure 1. A map of the study area.

The labor-intensive industries, in association with cash crop production, have transformed the spatial economy of the delta (Lo, 1989; Weng, 1998). The rapid economic development has brought about fundamental changes in land use and land cover patterns. The study aims to understand the land use and land cover dynamics using the techniques of remote sensing, GIS, and stochastic modelling.

\section{Methods}

\section{Land use and land cover change detection}

Land use and land cover patterns for 1989, 1994, and 1997 were mapped by the use of Landsat Thematic Mapper data (December 13, 1989, January 25, 1994, and August 29, 1997), which have a $30-\mathrm{m}$ ground resolution (except for the thermal IR band (band 6), which has a 120$\mathrm{m}$ resolution) and 7 spectral bands. A modified version of the Anderson scheme of land use/cover classification was adopted (Anderson et al., 1976). The categories include: (1) urban or built-up land, (2) barren land, (3) cropland (rice), (4) horticulture farms (primarily fruit trees), (5) dike-pond land, (6) forest, and (7) water.
Each Landsat image was enhanced using linear contrast stretching and histogram equalization to improve the image to help identify ground control points in rectification. The two dates of images were rectified to a common UTM coordinate system based on 1:50000 scale topographic maps. These data were resampled using the nearest Neighbor algorithm, so that the original brightness values of pixels were kept unchanged. The resultant root mean squared error was found to be 0.73 pixel (or $21.9 \mathrm{~m}$ on the ground) for the 1989 scene, 0.62 pixel $(18.6 \mathrm{~m})$ for the 1994 scene, and 0.58 pixel $(17.4 \mathrm{~m})$ for the 1997 scene.

Since this study requires the detection of fine changes in surface reflectances, radiometric correction became necessary. However, no ancillary data on the atmospheric conditions during the satellite overpasses were available to account for atmospheric differences between the two dates. A relative radiometric correction method using image regression (Jensen et al., 1995; Jensen, 1996) was therefore employed, by which the brightness value of each pixel of the subject scene (the 1989 scene) was related to that of the reference image (the 1997 scene) band by band to produce a linear regression equation. This image normalization method can minimize or eliminate the effects caused by using historical remotely sensed images of nonanniversary dates with varying sun angle, 
atmospheric, and soil moisture conditions (Jensen, 1996, pp. 116-119).

A supervised signature extraction with the maximum likelihood algorithm was employed to classify the Landsat images. Both statistical and graphical analyses of feature selection were conducted, and bands 2 (green), 3 (red), and 4 (near infrared) were found to be most effective in discriminating each class and thus used for classification. The feature selection process reduced the number of bands to be processed in the database, but should not affect the classification accuracy (Jensen, 1996). Training site data were collected by means of on-screen selection of polygonal training data method. A total of 140 training sites was chosen for each image to ensure that all spectral classes constituting each land use and land cover category were adequately represented in the training statistics. The accuracy of the three classified maps was checked with a stratified random sampling method, by which 50 samples were selected for each land use and land cover category. The reference data was collected from field survey or from existing land use and cover maps that have been field-checked. Largescale aerial photos were also employed as reference data in accuracy assessment when necessary.

In performing land use and land cover change detection, a cross-tabulation detection method was employed. A change matrix was produced. Quantitative areal data of the overall land use and land cover changes as well as gains and losses in each category between 1989 and 1997 can be compiled. The change matrix gives the knowledge of the main types of changes (directions) in the study area. In order to analyze the nature, rate, and location of land use and land cover changes, a set of 'gains' and 'losses' images for each category was also produced. These 'change' images was overlaid with an image of the county/city boundary, which was constructed in a vector GIS environment and converted into a raster format with the resolution of 30 meters. This GIS overlay intended to find land use and land cover change information within each county or city.

\section{Markovian analysis of the land use/cover change process}

Using land use and cover change data derived from satellite images, this study also establishes the validity of the Markov process for describing and projecting land use and cover changes in the delta, by examining statistical independence, Markovian compatibility, and stationarity of the data.
The testing of statistical independence hypothesis involves a procedure for comparing the expected numbers under the hypothesis with the actual data. If the number of land use and land cover categories is $M$, then the statistic to be computed is Karl Pearson's $\chi^{2}$ with $(M-1)^{2}$ degrees of freedom. This statistic may be called $K^{2}$ to differentiate it from its distribution $\left(\chi^{2}\right)$. Letting $N_{\text {ik }}$ stands for the number of cells having category i in 1989 and $\mathrm{k}$ in 1997 , and $\mathbf{N}_{\mathbf{i k}}$ for the expected number under the Markov hypothesis, the statistic is then

$$
K^{2}=\sum_{\mathrm{i}} \sum_{\mathrm{k}}\left(N_{\mathrm{ik}}-\mathbf{N}_{\mathbf{i k}}\right)^{2} / \mathbf{N}_{\mathbf{i k}}
$$

The 0.05 critical region for $M=7$ is thus any value of $K^{2}$ greater than $55 \cdot 8$. Any computed value of less than this critical number will lead to a conclusion that the data are compatible with the hypothesis of independence.

The computation of expected number $\mathbf{N}_{\mathbf{i k}}$ requires a direct application of the Chapman-Kolmogorov equation (Parzen, 1962; Stewart, 1994). According to the Markov hypothesis, the transition probability matrix governing the period 1989-1997 can be obtained by multiplying the 1989-1994 and 1994-1997 matrices. These transition probabilities can be computed with the aid of the GIS analysis function, and used in the following formula to calculate the expected numbers:

$$
\mathbf{N}_{\mathrm{ik}}=\sum_{\mathrm{j}}\left(N_{\mathrm{ij} .}\right)\left(N_{\mathrm{jk}}\right) / N_{\mathrm{j} .}
$$

where:

$N_{\mathrm{ij}}$. is the number of transitions from category

$\mathrm{i}$ to $\mathrm{j}$ during the period 1989 to 1994;

$N_{\text {.jk }}$ is the number of transitions from category

$\mathrm{j}$ to $\mathrm{k}$ during the period 1994 to 1997; and

$N_{\text {.j. }}$ is the number of hectares cells in category

$\mathrm{j}$ in 1994.

To test for first-order Markovian dependence, a chisquare goodness-of-fit test is used. This statistical test judges whether or not a particular distribution adequately describes a set of observations by making a comparison between the actual number of observations and the expected number of observations. The statistic is calculated from the relationship:

$$
\chi_{\mathrm{c}}^{2}=\sum_{\mathrm{i}} \sum_{\mathrm{k}}\left(O_{\mathrm{ik}}-E_{\mathrm{ik}}\right)^{2} / E_{\mathrm{ik}}
$$


where $O_{\mathrm{ik}}$ is the observed and $E_{\mathrm{ik}}$ the expected number of transition probability from 1989 to 1997. The distribution of $E_{\mathrm{ik}}$ is a Markovian distribution, however, the distribution of $\chi_{c}^{2}$ is a chi-square distribution with $(m-p-1)^{2}$ degrees of freedom where $\mathrm{m}$ is the dimension of the matrices, and $\mathrm{p}$ is the number of parameters estimated from the data. The hypothesis that the data are from the Markovian distribution is rejected if

$$
\chi_{\mathrm{c}}^{2}>\chi_{1-\mathrm{a},(\mathrm{m}-\mathrm{p}-1) 2}^{2}
$$

Finally, the hypothesis of stationarity is tested. The significance of stationarity of a Markovian process is that one can project future land development based on the current transition probabilities. According to the stationarity assumption, the changes recorded over the 5-year period from 1989 to 1994 and the 3-year period from the 1994 to 1997 result from the same transition mechanism. If so, then the 1989-1994 matrix can be used to predict the distribution of land use/cover categories in 1999, 2004, and so on, and the 1994-1997 matrix can be used to predict it to the year 2000, 2003, and so on. Indeed, they can both be used to project the distribution indefinitely into the future. The resulting equilibrium, or steady state distributions, may provide an indication of the ultimate trend of the land development process.

\section{Results}

\section{Land use and land cover change in the Zhujiang Delta}

The land use and land cover maps for 1989, 1994, and 1997 were produced from Landsat TM images and displayed in Figures 2-4 respectively. The overall accuracy of the land use/cover maps for 1989, 1994, and 1997 was determined to be 90.57 percent, 88.43 percent, and 85.43 percent respectively. The KAPPA indices for the 1989, 1994, and 1997 maps were $0.89,0.86$, and 0.83 respectively. Clearly, these data met the minimum standard of 85 percent stipulated by the USGS classification scheme (Anderson et al., 1976). Overall, the user's and producer's accuracies were high. The accuracy is therefore sufficient for evaluation of land use and land cover changes.

Table 1 shows the land use and land cover change matrix from 1989 to 1997. From the table, it is clear that there has been a considerable change (12.82\% of the total area) during the 8-year period. Urban or built-up land and horticulture farms have increased in area (by $47.68 \%$ and $88.66 \%$ respectively), and cropland has decreased in area (by $48 \cdot 37 \%$ ).

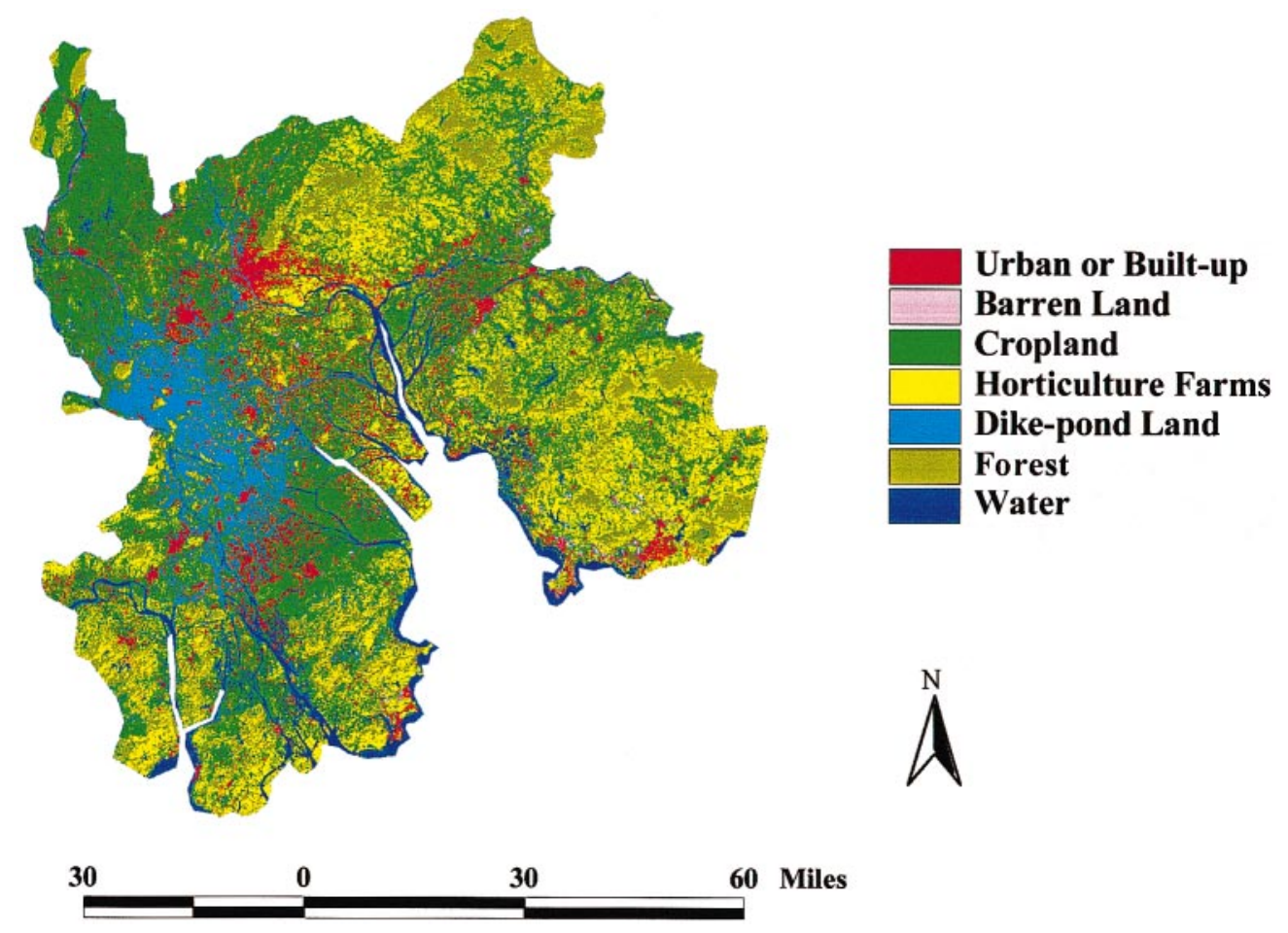

Figure 2. Land use and cover in the Zhujiang Delta, 1989. 


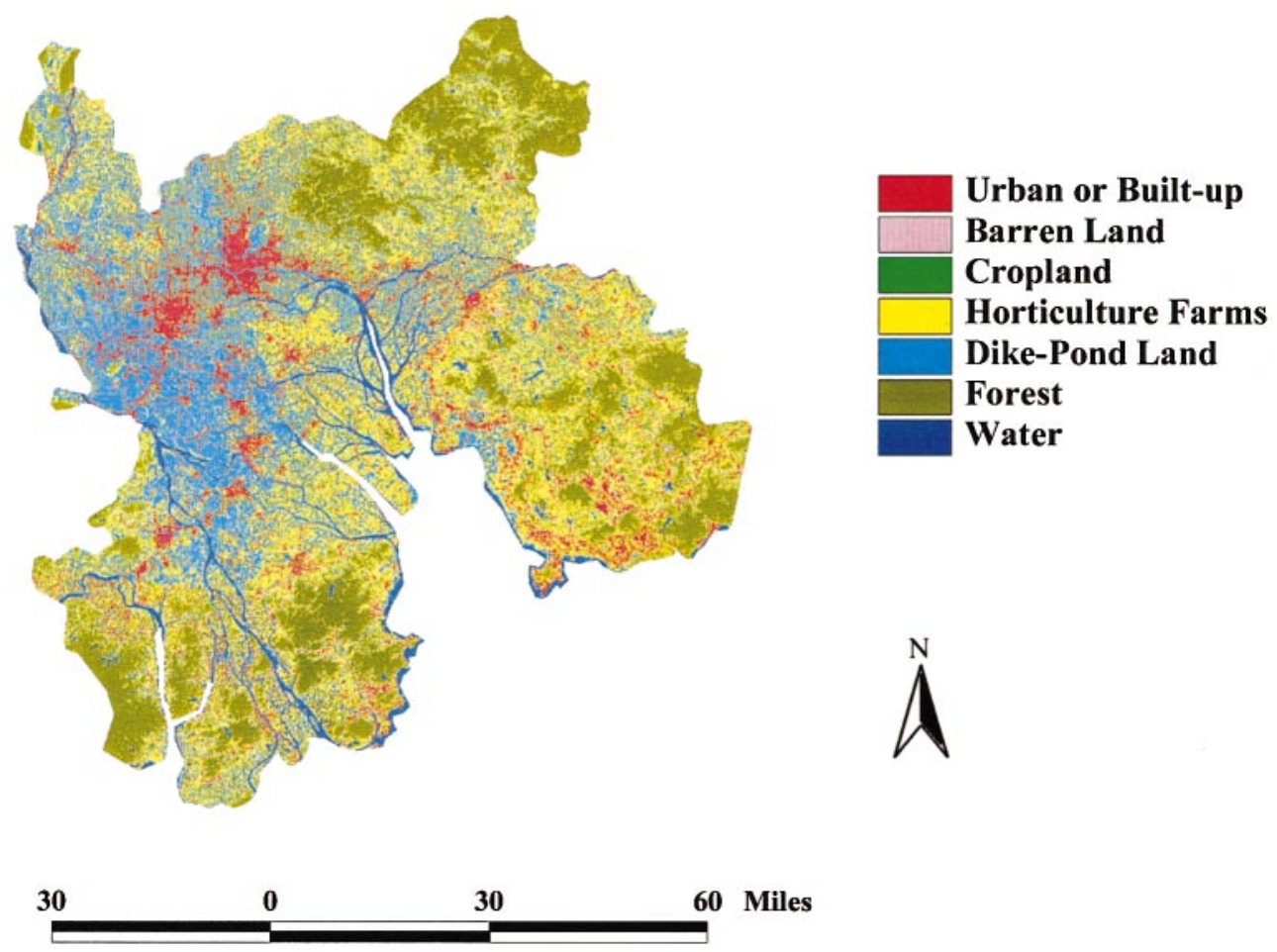

Figure 3. Land use and cover in the Zhujiang Delta, 1994.
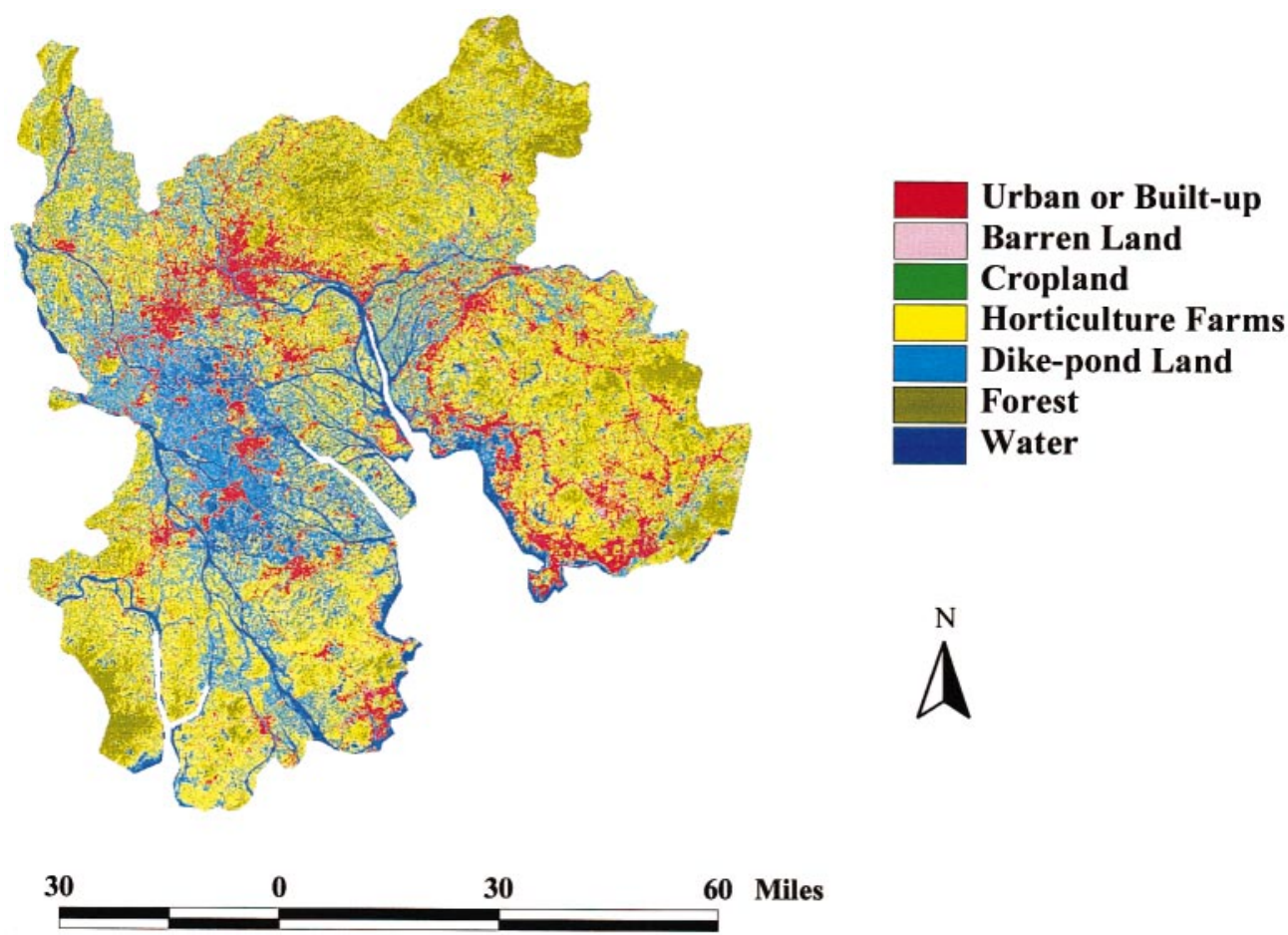

Figure 4. Land use and cover in the Zhujiang Delta, 1997.

The remote sensing-GIS analysis further indicates that of the 47.68 percent (65 690 hectares) increase in urban or built-up land, $37.92 \%$ results from cropland and $16.05 \%$ from horticulture farms. Barren land contributes $5.70 \%$ to the increase, totaling 11603.4 hectares. The overlay 
Table 1. Land use/cover change matrix, 1989-1997 (in hectares)

\begin{tabular}{|c|c|c|c|c|c|c|c|c|}
\hline \multirow[t]{2}{*}{1989} & \multicolumn{7}{|c|}{1997} & \multirow{2}{*}{$\begin{array}{l}1989 \\
\text { Total }\end{array}$} \\
\hline & $\begin{array}{l}\text { Urban or } \\
\text { built-up }\end{array}$ & $\begin{array}{l}\text { Barren } \\
\text { land }\end{array}$ & Cropland & $\begin{array}{l}\text { Horticulture } \\
\text { farms }\end{array}$ & $\begin{array}{l}\text { Dike-pond } \\
\text { land }\end{array}$ & Forest & Water & \\
\hline $\begin{array}{l}\text { Urban or } \\
\text { built-up }\end{array}$ & 54189 & $493 \cdot 38$ & $20890 \cdot 8$ & $35816 \cdot 8$ & 15887.4 & $3082 \cdot 77$ & $7407 \cdot 36$ & 137768 \\
\hline Barren land & $11603 \cdot 4$ & 661.77 & $4156 \cdot 02$ & $8690 \cdot 4$ & 1285.47 & 1414.53 & $1293 \cdot 75$ & 29105 \\
\hline Cropland & 77151.5 & $4651 \cdot 11$ & 152400 & 215536 & 55272.7 & $44497 \cdot 1$ & 29258.4 & 578767 \\
\hline $\begin{array}{l}\text { Horticulture } \\
\text { farms }\end{array}$ & $32660 \cdot 8$ & $3775 \cdot 23$ & 44972.9 & 132372 & $12850 \cdot 2$ & $43752 \cdot 3$ & $8222 \cdot 22$ & 278605 \\
\hline $\begin{array}{l}\text { Dike-pond } \\
\text { land }\end{array}$ & $14902 \cdot 8$ & 321.03 & 33931.4 & $20238 \cdot 6$ & $42489 \cdot 7$ & $2640 \cdot 96$ & 31327.4 & 145852 \\
\hline Forest & 8378.64 & 3028.59 & 26294.7 & 102589 & $3906 \cdot 72$ & 128048 & $5436 \cdot 81$ & 277683 \\
\hline Water & 4571.37 & 472.95 & $16156 \cdot 6$ & $10366 \cdot 1$ & $11179 \cdot 7$ & 1845.09 & 64414.3 & 109006 \\
\hline 1997 total & 203458 & 13404 & 298803 & 525609 & 142872 & 225281 & 147360 & 1556787 \\
\hline Change (ha) & 65690 & -15701 & -279964 & 247004 & -2980 & -52402 & 38354 & 702095 \\
\hline Change (\%) & +47.68 & -53.93 & $-48 \cdot 37$ & +88.66 & -0.02 & -18.87 & +3.19 & $12 \cdot 82$ \\
\hline
\end{tabular}

of the urban expansion map with a city/county mask reveals the spatial occurrence of urban expansion within administrative regions. Table 2 shows that in absolute term the greatest urban expansion occurred in Dongguan (+23 478.90 ha), Bao'an (+14941.08 ha), Nanhai (8004.1 ha), and Zhuhai (+5869.71 ha). However, in percentage term, the largest increase in urban or built-up land occurred in Zhuhai (1100.00\%), followed by Shenzhen (306.65\%), Bao'an (233.33\%), and Dongguan (125.71\%). Massive urban sprawl in these areas can be ascribed to rural urbanization, which is a common phenomenon in post-reform China. Rapid urban development in the form of small towns in the east side of the delta is highly influenced by the investment from Hong Kong (Yeh and Li, 1996). In contrast, old cities such as Guangzhou and Foshan, do not show a rapid increase in urban or built-up land because they have no land on which to expand further (as they have already expanded fully in the past) and the concentration of urban enterprises is in the city proper. Shenzhen and Zhuhai were designated as Special Economic Zones at the same time, but the pace of urbanization in the two cities has been quite different. Urban development in Shenzhen had largely been completed in the 1980s, while Zhuhai's urban expansion appears primarily during the period 1989-1997 (+5869.71 ha).

During the same period, cropland has decreased by $48.37 \%$ in the study area. The cross-tabulation of the 1989 and 1997 land use/cover maps reveals that most of the losses were converted to horticulture farms (215536 ha) and to urban or built-up land (77 151.5 ha). The vast conversion of cropland to horticulture farms has much to do with a recent shift in agricultural production policy, in which
Table 2. Satellite-detected urban expansion and cropland loss in the Zhujiang Delta, 1989-1997

\begin{tabular}{lrrrr}
\hline $\begin{array}{l}\text { City/ } \\
\text { county }\end{array}$ & $\begin{array}{c}\text { Urban } \\
\text { change } \\
\text { (ha) }\end{array}$ & $\begin{array}{c}\text { Urban } \\
\text { change } \\
(\%)\end{array}$ & $\begin{array}{c}\text { Cropland } \\
\text { change } \\
\text { (ha) }\end{array}$ & $\begin{array}{c}\text { Cropland } \\
\text { change } \\
(\%)\end{array}$ \\
\hline Baoan & 14941.08 & 233.33 & -4268.90 & -16.33 \\
Dongguan & 23478.90 & 125.71 & -62965.90 & -64.13 \\
Doumen & 1600.83 & 75.00 & -6403.30 & -28.57 \\
Foshan & 533.61 & 8.33 & -3201.66 & -85.71 \\
Guangzhou & 4802.50 & 20.45 & -21344.40 & -47.62 \\
Jiangmen & 2134.44 & 133.33 & -2134.44 & -50.00 \\
Nanhai & 8004.10 & 60.00 & -28281.30 & -50.96 \\
Panyu & 1067.22 & 14.29 & -18676.40 & -52.24 \\
Sanshui & 0.00 & 0.00 & -37886.30 & -54.62 \\
Shenzhen & 3219.12 & 306.65 & -3201.66 & -75.00 \\
Shunde & 3735.28 & 58.33 & -2134.40 & -13.33 \\
Xinhui & 1601.44 & 27.27 & -22411.60 & -42.86 \\
Zengcheng & 0.00 & 0.00 & -24546.10 & -47.92 \\
Zhongshan & 3201.60 & 24.00 & -43222.40 & -58.27 \\
Zhuhai & 5869.71 & 1100.00 & -4268.88 & -61.54 \\
\hline
\end{tabular}

cash crops such as fruit, vegetables, and flowers are highly advocated. A query regarding the location and dimension of the land use/cover change indicates that cropland loss occurred largely in three areas. A major cluster emerged in Sanshui and Nanhai, where the Beijiang River and Xijiang River converge to produce a vast area of fertile alluvial deposits. A second cluster appeared in the central part of Zhongshan. Field surveys indicate that sandy fields (Sha Tian) occupy this area, a major type of paddy soil that intensive agricultural activities have modified into a high yielding cropland. A third cluster of cropland loss was observed in the estuary of the East River, which had been the only major paddy cultivation region in the east side of the delta. These observations suggest that most of the 
cropland loss occurred in good-quality agricultural land. Therefore, the sustainability of agriculture is questionable given that this trend of land use and land cover change continues. The overlay of cropland loss map with a city mask makes it possible for generating the statistics of cropland loss found in each city/county (Table 2). These figures are useful for examining the relationship between cropland loss and socio-economic drivers of land use and land cover change.

\section{Stability of the land use/cover change process}

The transition probabilities governing the periods 1989-1994, 1994-1997, and 1989-1997 are calculated. Table 3 shows transitional probabilities (TPs) between 1989 and 1997. For instance, the TP from barren land to urban/built-up was 0.267 ; from cropland 0.1132; from horticultural farms 0.0897, and so forth. This computation is based on the actual number of observations in land use and land cover change during the same period regardless of the way that the change process occurred.

The expected TPs between 1989 and 1997 under the Markov hypothesis are also calculated and displayed in Table 4 . They were obtained by multiplying the periods 1989-1994 and 1994-1997 matrices using Chapman-Kolmogorov. From Table 4, it is noted that the TP to urban/built-up from barren land would be 0.1735 ; from cropland 0.1225 ; and from horticultural farms 0.0972, if the land use and land cover change process was Markovian.

The computed value of the statistic $\mathrm{K}^{2}$ is $1 \cdot 6425 * 10^{5}$, much greater than $55 \cdot 8$. The hypothesis of statistical independence is therefore rejected. The land use and land cover change data are statistically dependent, but the question is whether this dependence can be characterized by first-order Markov dependence, or by a higher order dependence.

The computed value of $\chi_{c}^{2}$ is 0.5731 . The degree of freedom is 36 since two parameters $\left(\mu_{\mathrm{x}}\right.$ and $\left.\delta_{\mathrm{x}}^{2}\right)$ are estimated from the normal distribution. For $\alpha=0.05$, the value of $\chi_{0.9536}^{2}$ is 29.1 . The hypothesis is thus accepted. In other words, it can be hypothesized that the data are generated by a Markov process at a risk of $5 \%$.

Whether the land use and land cover change process in the delta has been stabilized is a more critical issue relating to land development policies. To answer this question, steady state probabilities in the three different periods are computed and compared (Table 5). These numbers show the probabilities that a land cell will be in the different categories at a sufficiently distant point in time. A short inspection of this table indicates

Table 3. Land use transitional probabilities, 1989-1997

\begin{tabular}{|c|c|c|c|c|c|c|c|}
\hline \multirow[t]{2}{*}{1989} & \multicolumn{7}{|c|}{1997} \\
\hline & $\begin{array}{l}\text { Urban or } \\
\text { built-up }\end{array}$ & $\begin{array}{c}\text { Barren } \\
\text { land }\end{array}$ & Cropland & $\begin{array}{l}\text { Horticulture } \\
\text { farms }\end{array}$ & $\begin{array}{l}\text { Dike-pond } \\
\text { land }\end{array}$ & Forest & Water \\
\hline Urban or built-up & 0.3454 & 0.0042 & 0.1607 & 0.2899 & 0.1101 & 0.0353 & 0.0545 \\
\hline Barren land & 0.267 & 0.0195 & 0.183 & 0.3651 & 0.0505 & 0.0669 & 0.0481 \\
\hline Cropland & 0.1132 & 0.0082 & 0.2579 & 0.3923 & 0.0864 & 0.0915 & 0.0505 \\
\hline Horticulture farms & 0.0897 & 0.0126 & 0.157 & 0.479 & 0.0395 & 0.1894 & 0.0328 \\
\hline Dike-pond land & 0.0982 & 0.0024 & 0.2335 & 0.1485 & 0.2754 & 0.0324 & 0.2096 \\
\hline Forest & 0.0219 & 0.0078 & 0.0962 & 0.3674 & 0.0141 & 0.4695 & 0.023 \\
\hline Water & 0.0077 & 0.001 & 0.027 & 0.0196 & 0.0198 & 0.0041 & 0.9206 \\
\hline
\end{tabular}

Table 4. Expected values of land use/cover transitional probabilities under Markov hypothesis, 1989-1997

\begin{tabular}{|c|c|c|c|c|c|c|c|}
\hline \multirow[t]{2}{*}{1989} & \multicolumn{7}{|c|}{1997} \\
\hline & $\begin{array}{l}\text { Urban or } \\
\text { built-up }\end{array}$ & $\begin{array}{l}\text { Barren } \\
\text { land }\end{array}$ & Cropland & $\begin{array}{l}\text { Horticulture } \\
\text { farms }\end{array}$ & $\begin{array}{l}\text { Dike-pond } \\
\text { land }\end{array}$ & Forest & Water \\
\hline Urban or built-up & 0.2122 & 0.0120 & 0.1842 & 0.3334 & 0.0939 & 0.0851 & 0.0792 \\
\hline Barren land & 0.1735 & 0.0121 & 0.1862 & 0.3817 & 0.0759 & 0.0983 & 0.0723 \\
\hline Cropland & 0.1225 & 0.0089 & 0.2114 & 0.3723 & 0.0904 & 0.1134 & 0.0811 \\
\hline Horticulture farms & 0.0972 & 0.0085 & 0.1761 & 0.3858 & 0.0602 & 0.2090 & 0.0633 \\
\hline Dike-pond land & 0.1049 & 0.0062 & 0.2306 & 0.2475 & 0.1558 & 0.0709 & 0.1841 \\
\hline Forest & 0.0441 & 0.0063 & 0.1357 & 0.3803 & 0.0328 & 0.3526 & 0.0484 \\
\hline Water & 0.0145 & 0.0013 & 0.0339 & 0.0445 & 0.0207 & 0.0156 & 0.8696 \\
\hline
\end{tabular}


Table 5. A comparison of steady state probabilities

\begin{tabular}{lcccccrr}
\hline & $\begin{array}{c}\text { Urban or } \\
\text { built-up }\end{array}$ & $\begin{array}{c}\text { Barren } \\
\text { land }\end{array}$ & Cropland & $\begin{array}{c}\text { Horticulture } \\
\text { farms }\end{array}$ & $\begin{array}{c}\text { Dike-pond } \\
\text { land }\end{array}$ & Forest & Water \\
\hline $1989-1997$ & 0.0714 & 0.0058 & 0.1137 & 0.2419 & 0.0510 & 0.1176 & 0.3939 \\
$1989-1994$ & 0.0817 & 0.0082 & 0.1327 & 0.2303 & 0.1055 & 0.3126 & 0.1317 \\
$1994-1997$ & 0.0431 & 0.0032 & 0.0688 & 0.1226 & 0.0308 & 0.0446 & 0.6870 \\
\hline
\end{tabular}

that the three distributions are distinctly different, implying the differences in transition mechanism. The 1994-1997 distribution is particularly different from the other two. As a result, the idea that the process is stationary may be rejected although this assumption has not been thoroughly tested as a hypothesis. However, if the three transition matrices are to continue in a stationary manner, the distribution of land use/cover categories can be projected for a remote future: $7 \cdot 14 \%$ of the land will be urban or built-up, $0.58 \%$ will be barren land, $11.37 \%$ will be cropland, $24.19 \%$ will be horticulture farms, $5.1 \%$ will be dike-pond land, $11.76 \%$ will be forest, and $39.39 \%$ will be water.

\section{Discussion and conclusions}

This paper describes how the technologies of satellite remote sensing, GIS and stochastic modelling are combined to address land use and land cover changes in the Zhujiang Delta, China, during the period 1989-1997. It was found that urban or built-up land and horticulture farms have notably increased in area, while cropland has decreased. Urban land development was uneven in different parts of the delta, and was closely related to the loss of cropland. The land use development has not been stabilized, and the two study periods of time (1989-1994 and 1994-1997) had different transition mechanisms.

The use of Landsat TM data to detect land use and land cover changes has been generally a success. The digital image classification coupled with GIS has demonstrated its ability to provide comprehensive information on the direction, nature, rate, and location of land use and land cover changes as a result of rapid industrialization and urbanization. However, the issue of class uncertainties in image classification has not been examined in this paper. Although the land use and land cover maps have a reasonably high overall accuracy, the accuracy of different classes varies. The horticulture farms class was confused with several other classes due to their diversity. This confusion has hindered the obtainment of accurate TPs. Moreover. the image classification method used in this study was not spatially implicit. The method thus has a limitation in improving image classification accuracy for individual classes.

The Markov chain models have shown the capabilities of descriptive power and simple trend projection for land use and land cover change, regardless of whether or not the trend actually persists. The analysis can serve as an indicator of the direction and magnitude of change in the future as well as a quantitative description of change in the past. There are several limitations in land use and land cover change applications, however. First, these models are difficult to accommodate high-order effects. Baker (1989) suggests that these effects can be modeled by redefining the state space, so that new states are defined by both present and preceding states. A second-order model, for instance, would include $\mathrm{m}^{2}$ states instead of $\mathrm{m}$ states in a first-order model. Second, the influence of exogenous and endogenous variables to the transitions, i.e. non-stationary transitions, cannot be incorporated into the models so that land use and land cover change processes can be understood. This limitation can be addressed by using one of the two approaches: setting TPs as a function of these variables (which can vary in both time and space), or switching between different stationary transition matrices (Baker, 1989). Finally, spatial dependence of transitions is not accounted for in simple constant-transition models. Turner (1987) shows a method to conditioning changes to the initial states in adjacent sites, in addition to conditioning changes in the initial states, and therefore introduces spatial dependence into Markov modelling.

The issue of obtaining observed TPs is crucial. Early Markov models were parameterized using data observed and measured from field surveys and air photography. These data tended to be biased and costly. The use of satellite remote sensing enables us to calculate less biased TPs from the full extent of the landscape (Hall et al., 1991; Paster and Johnson, 1992). In addition, remotely sensed data are cost-effective, multiple-date, and ready to input into GIS.

The ability of GIS to integrate spatial data from different sources, with different formats, 
structures, projections, or levels of resolution is especially useful in land use and land cover studies. Quantifying temporal change often involves using such sources as historical maps, air photos, and satellite images. Changes in the spatial distribution of land classes can be summarized by overlaying maps of different dates and analyzing their spatial coincidence. Changes from one land class to another can be mathematically described as probabilities that a given pixel will remain in the same state or be converted to another state (Johnson, 1993). The use of GIS with digitized maps provides more precision in determining TPs over different portions of the landscape at different times, removing many of the difficulties in early works of parameterizing Markov matrices (Johnson et al., 1996).

The integration of satellite remote sensing, GIS, and Markov modelling provides a means of moving the emphasis of land use and land cover change studies from patterns to processes. Data and computational limits are becoming less significant due to advances in remotes sensing for change detection and in the incorporation of remotely sensed data and auxiliary data into GIS (Baker, 1989). The most compelling research issues may be a lack of appreciation of the power of the integration and understanding of how to incorporate existing knowledge in useful models of land use and land cover change.

\section{Acknowledgements}

The author wishes to thank anonymous reviewers for their useful comments and suggestions that help to improve this paper. The funded support of the National Geographic Society through Dr. C. P. Lo, which made our fieldwork possible, is also greatly acknowledged.

\section{References}

Baker, W. L. (1989). A review of models of landscape change. Landscape Ecology 2, 111-133.

Bell, E. J. (1974). Markov analysis of land use change: an application of stochastic processes to remotely sensed data. Socio-Econ Planning Science 8, 311-316.

Bell, E. J. and Hinojosa, R. C. (1977). Markov analysis of land use change: continuous time and stationary processes. Socio-Econ Planning Science 11, 13-17.

Bourne, L. S. (1971). Physical adjustment processes and land use succession: a review and central city example. Economic Geography 47, 1-15.

Brown, D. G., Pijanowski, B. C. and Duh, J. D. (2000). Modelling the relationships between land use and land cover on private lands in the Upper Midwest, USA. Journal of Environmental Management 59, 247-263.
Chen, S., Zeng, S. and Xie, C. (2000). Remote sensing and GIS for urban growth analysis in China. Photogrammetric Engineering and Remote Sensing 66, 593-598.

Clarke, K. C., Hoppen, S. and Gaydos, L. (1997). A self-modifying cellular automaton model of historical urbanization in the San Francisco Bay area. Environment and Planning B: Planning and Design 24, 247-261.

Clarke, K. C. and Gaydos, L. J. (1998). Loose-coupling a cellular automaton model and GIS: long-term urban growth prediction for San Francisco and Washington/Baltimore. International Journal of Geographical Information Science 12, 699-714.

Dai, C., Tang, L., Jiang, P. and Lin, J. (1996). Satellite remote sensing for monitoring urban expansion and environmental remediation. In Population Dynamics and Management of Urban Environment, pp. 9-16. Beijing: The $47^{\text {th }}$ IAF Congress.

Drewett, J. R. (1969). A stochastic model of the land conversion process. Regional Studies 3, 269-280.

Ehlers, M., Jadkowski, M. A., Howard, R. R. and Brostuen, D. E. (1990). Application of SPOT data for regional growth analysis and local planning. Photogrammetric Engineering and Remote Sensing 56, 175-180.

Geohegan, J., Wainger, L. A. and Bockstael, N. E. (1997). Spatial landscape indices in a hedonic framework: an ecological economics analysis using GIS. Ecological Economics 23, 251-264.

Gong, Z. and Chen, Z. (1964). The soils of the Zhujiang River Delta. Journal of Soils 36, 69-124 (In Chinese).

Haan, C. T. (1977). Statistical Methods in Hydrology. Ames, Iowa: The Iowa State University Press.

Hall, F. G., Botkin, D. B., Strebel, D. E., Woods, K. D. and Goetz, S. J. (1991). Large-scale patterns of forest succession as determined by remote sensing. Ecology 72, 628-640.

Harris, P. M. and Ventura, S. J. (1995). The integration of geographic data with remotely sensed imagery to improve classification in an urban area. Photogrammetric Engineering and Remote Sensing 61, 993-998.

Huber, W. (2001). Estimating Markov transitions. Journal of Environmental Managements 61, 381-385.

Jahan, S. (1986). The determination of stability and similarity of Markovian land use change processes: a theoretical and empirical analysis. Socio-Econ Planning Science 20, 243-251.

Jensen, J. R. (1996). Introductory Digital Image Processing: A Remote Sensing Perspective (2nd edn). Upper Saddle River, NJ: Prentice Hall.

Johnson, C. (1993). Introduction to quantitative methods and modelling in community, population, and landscape ecology. In Environment Modelling with GIS (M. F. Goodchild, B. O. Parks and L. T. Steyaert, eds), pp. 276-283. Oxford: Oxford University Press.

Johnson, C. A., Cohen, Y. and Pastor, J. (1996). Modelling of spatially static and dynamic ecological processes. In GIS and Environment Modelling: Progress and Research Issues (M. F. Goodchild, L. T. Steyaert, B. O. Parks, et al., eds), pp. 149-154. Fort Collins, CO: GIS World, Inc.

Lanbin, E. F. (1997). Modelling and monitoring landcover change processes in tropical regions. Progress in Physical Geography 21, 375-393. 
Landis, J. D. (1994). The California urban future model: a new-generation of metropolitan simulation-models. Environment and Planning B 21, 399-420.

Lo, C. P. (1989). Recent spatial restructuring in Zhujiang Delta, South China: a study of socialist regional development strategy. Annals of the Association of the American Geographers 79, 293-308.

Meaille, R. and Wald, L. (1990). Using geographic information system and satellite imagery within a numerical simulation of regional urban growth. International Journal of Geographic Information Systems 4, 445-456.

Muller, R. M. and Middleton, J. (1994). A Markov model of land-use change dynamics in the Niagara region, Ontario, Canada. Landscape Ecology 9, 151-157.

Parzen, E. (1962). Stochastic Processes. San Francisco: Holden-Day.

Pastor, J. and Johnson, C. A. (1992). Using simulation models and geographic information systems to integrate ecosystem and landscape ecology. In New Perspectives for Watershed Management, pp. 324-346. New York: Springer-Verlag.

Robinson, V. B. (1978). Information theory and sequences of land use: an application. The Professional Geographer 30, 174-179.

Ruddle, K. and Zhong, G. (1988). Integrated AgricultureAquaculture in South China: the Dike-Pond System of the Zhujiang Delta. Cambridge, UK: Cambridge University Press.

Steininger, M. K. (1996). Tropical secondary forest regrowth in the Amazon: age, area and change estimation with Thematic Mapper data. International Journal of Remote Sensing 17, 9-27.

Stewart, W. J. (1994). Introduction to the Numerical Solution of Markov Chains. Princeton, NJ: Princeton University Press.

Theobald, D. M. and Hobbs, N. T. (1998). Forecasting rural land-use change: a comparison of regressionand spatial transition-based models. Geographical and Environmental Modelling 2, 65-82.

Treitz, P. M., Howard, P. J. and Gong, P. (1992) Application of satellite and GIS technologies for land-cover and land-use mapping at the rural-urban fringe: a case study. Photogrammetric Engineering and Remote Sensing 58, 439-448.
Turner, M. G. (1987). Spatial simulation of landscape changes in Georgia: a comparison of three transition models. Landscape Ecology 1, 29-36.

Turner, M. G., Wear, D. N. and Flamm, R. O. (1996). Land ownership and land-cover change in the southern Appalachian highlands and the Olympic peninsula. Ecological Applications 6, 1150-1172.

Verburg, P. H. and Chen, Y. (2000). Multiscale characterization of land-use patterns in China. Ecosystems 3 , 369-385.

Wang, X. (1986). Multivariate Statistical Analysis of Geological Data. Beijing, China: Science Press. (In Chinese)

Wear, D. N., Turner, M. G. and Naiman, R. J. (1998). Land cover along an urban-rural gradient: implications for water quality. Ecological Applications 8, 619-630.

Weng, Q. (1998). Local impacts of the post-Mao development strategy: the case of the Zhujiang Delta, southern China. International Journal of Urban and Regional Studies 22, 425-442.

Weng, Q. (2001). A remote sensing-GIS evaluation of urban expansion and its impact on surface temperature in the Zhujiang Delta, China. International Journal of Remote Sensing, Forthcoming.

Westmoreland, S. and Stow, D. A. (1992). Category identification of changed land-use polygons in an integrated image processing/geographic information system. Photogrammetric Engineering and Remote Sensing 58, 1593-1599.

Yeh, A. G. O. and Li, X. (1996). Urban growth management in the Pearl River delta - an integrated remote sensing and GIS approach. The ITC Journal 1, 77-85.

Yeh, A. G. O. and Li, X. (1997). An integrated remote sensing-GIS approach in the monitoring and evaluation of rapid urban growth for sustainable development in the Pearl River Delta, China. International Planning Studies 2, 193-210.

Yeh, A. G. O. and Li, X. (1999). Economic development and agricultural land loss in the Pearl River Delta, China. Habitat International 23, 373-390.

Zhong, G. (1980). The mulberry dike-fish pond system in the Zhujiang Delta: a man-made ecosystem of land-water interaction. Acta Geographica Sinica 35, 200-212. (In Chinese) 